\title{
NEW RELEASES
}

\section{The Taliban revival}

\author{
Hassan Abbas \\ Yale University Press, New Haven, CT, 2014, 262pp., \$30.00, ISBN: 978-0300178845
}

International Politics Reviews (2015) 3, 34. doi:10.1057/ipr.2015.4

\section{Elizabeth Bennett}

New York University, New York, USA.

E-mail: Elizabeth.Bennett@nyu.edu

The book The Taliban Revival: Violence and Extremism on the Pakistan-Afghanistan Frontier by National Defense University professor Dr Hassan Abbas focuses on the resurgence of the Taliban and how they threaten any hope for stability in Afghanistan and Pakistan. This book is timely and represents an important contribution to the study of the Taliban and the underlying political and cultural context. Abbas brings fresh insight with his analysis, but also from his reflections, from working in Pakistan as a police officer in the Khyber Pakhtunkhwa province and Federally Administered Tribal Areas. So while the war in Afghanistan ended on 28 December 2014 the threat of the Taliban persists. And as the United States devises and implements a plan for long lasting stability in Afghanistan this work provides a crucial review as to why the Taliban rebounded after their defeat in 2001-2002.

The book is set in a post 9/11 context but traces the history of the Afghan Taliban and the Pakistani Taliban from the early 1990s. This includes an examination of the Taliban culture and traditions and where they fit into Pashtun history. Next after the fall of the Taliban government in October 2001, Abbas sets the stage for the Taliban revival in Afghanistan via sanctuaries across the border in Pakistan. This brings the book to 2007-2013 with the rise of the Pakistani Taliban and the loss of the SWAT valley. Lastly the book covers the impact on the Taliban revival from regional and local politics, as well as the US drone program successes and controversies.

Abbas argues there are various actors and underlying reasons that hinder the chance of preventing a Taliban revival, from a US strategy that lacks understanding of the history and culture of the Taliban to the lawlessness and criminal elements the group exploits. To that point, The Taliban Revival is able to do what many others had issues with: it crosses the Af-Pak border to provide useful background and analysis. It depicts what happened in Pakistan and the decision-making in Islamabad, the situation in the Afghanistan and Kabul, but most importantly what it was like on the frontier in a post-9/11 world.

One of the book's strengths is the study on the differences between the Afghan and the Pakistani Taliban and the general misunderstanding of how these groups fit into the history of the region, their role in the war, and the threat they pose to stability in Afghanistan and Pakistan. Capturing these differences Abbas writes on this, 'Similar in ideological mindset and military capability, they look in different directions.' This differentiation of the groups brings so much of what has been missing from the discourse on the Taliban and militancy in Afghanistan.

From the straightforward case presented by Abbas, it is easy to contextualize the strengths and weakness of US strategy and grasp the real and present struggle that lay ahead to secure stability in Afghanistan and Pakistan. Abbas concludes with a few recommendations for stability: strengthen law enforcement, find a legitimate steady stream of revenue for the Afghan government, engage in dialog with militant groups and promote religious harmony. And while these recommendations are well-detailed and built on the foundation of the rule of law the prospects seem dim. But in the end Abbas writes, 'Time is running out, but the Talibanization trends can be reversed.' 